smoking 25 cigarettes a day (Office of Health Economics, 1969) is almost certainly untrue, but it may well deter some smokers from making the effort to give up smoking and encourage some ex-smokers to return to the habit.

The aetiology of coronary heart disease, which now accounts for more than a quarter of all deaths among U.K. men aged 35 and over, is complex. As the report of the Royal College of Physicians (1971) points out, the risk of cigarette smoking is clearly established within lower and higher levels of the risk factors of high blood pressure, high blood cholesterol, and low physical activity. Surprisingly, the risk of obesity is not mentioned. The same report points out that lung cancer and chronic bronchitis together account for $17 \%$ of all deaths in men aged 35 and over, and the causal relationship of these two diseases with smoking is also well documented. The overall loss of life expectancy shown in the prospective study of British doctors (Doll and Hill, 1964) is strikingly related to amount smoked. Over $80 \%$ of the non-smoking doctors aged 35 are expected to survive the retiring age of 65 compared with only $60 \%$ of those smoking 25 or more cigarettes (Royal College of Physicians, 1971).

There is no doubt that smoking and obesity are both serious health hazards. Because of the inverse relationship between smoking and obesity there is, therefore, clearly a need for morbidity and mortality studies on the interrelation between the two hazards and their relative importance.

A generous grant from the Nuffield Foundation made this investigation possible. It is with pleasure that we acknowledge our indebtedness to Richard Thomas and Baldwins Limited and the Steel Company of Wales Limited for permission to carry out the investigation, and to their managements and the trades unions for their support while it was in progress. Finally, we wish to express our gratitude to Dr. J. Howlett and Mrs. J. Lay, of the Atlas Computer Laboratory, Chilton, Berks, for the invaluable help they and their staff gave us with the analysis of our data.

\section{References}

Ashcroft, M. T., Ling, J., Lovell, H. G., and Maill, W. E. (1966). British fournal of Preventive and Social Medicine, 20, 22.

Clark, D. A., Allen, M. G., and Wilson, F. H. (1967). American fournal of Clinical Nutrition, 20,743.

Doll, R., and Hill, A. B. (1964). British Medical fournal, 1, 1399, 1460.

Emery, F. E., Hilgendorf, E. L., and Irving, B. L. (1968). The Psychological Dynamics of Smoking. Tobacco Research Council Paper No. 10, London.

Fox, S. M. (1966). Obesity and Health. U.S. Department of Health, Education and Welfare. Publication No. 1485. p. 45.

Kahn, H. A. (1966). The Dorn Study of Smoking and Mortality Among U.S. Veterans: Report on eight and a half years of Observations. National Veterans: Report on eight and a half years
Cancer Institute Monograph, No. 19, p. 1.

Khosla, T., and Lowe, C. R. (1967). British fournal of Preventive and Social Medicine, 21, 122 .

Khosla, T., and Lowe, C. R. (1968). Lancet, 1, 742.

Lowe, C. R., et al. (1968). British fournal of Preventive and Social Medicine, $22,1,1$.

Metropolitan Life Insurance Company (1959). Statistical Bulletin, vol. 40.

Office of Health Economics (1969). Obesity and Disease, London.

Registrar General (1965). Statistical Review of England and Wales Part 1. London, H.M.S.O.

Royal College of Physicians (1971). Smoking and Health Now, p. 102. London, Pitman Medical and Scientific Publishing Co.

Society of Actuaries (1959). Build and Blood Pressure Study. Chicago.

Stoudt, H. W., Damon, A., McFarland, R., and Roberts, J. (1965) Weight, Height and Selected Body Dimensions Service Publication No. 1000, Vital Health Statistics Series 11, No. 8.

\title{
Intravenous Diazepam for Direct-current Cardioversion
}

\author{
K. SOMERS, \\ R. F. GUNSTONE, \\ ASHVIN K. PATEL, \\ P. G. D'ARBELA
}

British Medical fournal, 1971, 4, 13-15

\section{Summary}

The induction of anaesthesia with intravenous diazepam is a valuable contribution to the simpler use of cardioversion and is the method of choice because it is readily available for elective cardioversion. Fifty-six cardioversion procedures were carried out by this method in an African hospital. No special premedication or drug preparation was used. There were no hazards apart from transient apnoea in two patients and persisting amnesia in one patient.

\section{Introduction}

The treatment of cardiac arrhythmias by direct-current countershock is now an established procedure since its introduction by Lown et al. (1962). Brief general anaesthesia is necessary for

\section{Makerere University Medical School, Kampala, Uganda}

K. SOMERS, F.R.C.P., D.C.H., Clinical Professor of Medicine, Chief of the Division of Cardiology

R. F. GUNSTONE, M.B., M.R.C.P., Senior Registrar in Medicine (At present Consultant Physician, Walsgrove General Hospital, Coventry)

ASHVIN K. PATEL, M.B., M.MED., Senior Registrar in Medicine (Present address: Veterans Administration Hospital, Madison, Wisconsin 53705 U.S.A.)

P. G. D'ARBELA, M.B., M.R.C.P., Senior Lecturer in Medicine electric cardioversion, which can be a painful procedure. For elective cardioversion of atrial fibrillation, especially in rheumatic heart disease, it is desirable to prepare patients by previous anticoagulation for two to three weeks to avoid risks of thromboembolism. In addition, it is customary to stop digitalis preparations for at least four days to safeguard against the risks of digitalis associated arrhythmias. It is usual to start maintenance quinidine therapy one to two days before an elective procedure in order to prevent a recurrence of the arrhythmia. A sedative may be given just before the procedure.

Since earlier reports on the value and simplicity of diazepam administered intravenously as a short-acting hypnotic for cardioversion (Nutter and Massumi, 1965; Kernohan, 1966) and its advantages compared with thiopentone (Muenster et al., 1967), there have been several supplementary reports from various centres (Kernohan, 1967; Winters et al., 1968; Hendrix, 1969; Lebowitz, 1969; Turkel and Lemmert, 1969; Woodbridge, 1969) commenting on the safety and convenience of the method.

The ideal circumstances of previous preparation are not easily achieved in developing countries where pressure on bed space and professional manpower can be excessive. Accordingly, the experience of cardioversion with intravenous diazepam alone reported in this paper is relevant to clinics with humble facilities. In so doing we confirm that electrical cardioversion as an elective procedure can be simplified further with the involvement of minimum personnel and at outpatient or day admission arrangement. The technique we describe has its theoretical hazards. It is, however, based on a reasonable balance of risks in the circumstances prevailing in developing countries. 


\section{Methods and Results}

Fifty-three consecutive patients ( 25 males, 27 females) were treated with direct-current cardioversion. One patient was treated twice, another three times, totalling 56 procedures in all. Their age range was 8 to 66 years. The most frequent underlying heart diseases encountered were rheumatic heart disease and endomyocardial fibrosis. Cardioversion was also carried out in patients with "congestive cardiomyopathy," ischaemic heart disease, constrictive pericarditis (postoperative), atrial septal defect (postoperative), and lone atrial flutter, atrial fibrillation, and ventricular tachycardia (Table I). The types of arrhythmia treated are shown in Table II.

TABLE I-Clinical Diagnosis in 53 Cases of Arrhythmia Treated with Diazepam and Direct-current Shock

Rheumatic heart disease Rndomyocardial fibrosis Endomyocardial fibrosis Congestive cardiomyopathi Constrictive pericarditis (postoperative) Atrial septal defect (postoperative) Myocarditis Lone atrial flutter or atriai fibrillation Ventricular tachycardi

Supraventricular tachycardia

*13 postmitral valvotomy.

TABLE II-Arrhythmias Treated with Diazepam and Direct-current Shock

\begin{tabular}{|c|c|c|c|}
\hline \multicolumn{2}{|l|}{ Arrhythmia } & \multirow{2}{*}{ 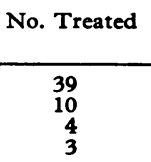 } & \multirow{2}{*}{$\begin{array}{c}\begin{array}{c}\text { Reversion to } \\
\text { Sinus Rhythm }\end{array} \\
25 \\
9 \\
4 \\
2\end{array}$} \\
\hline $\begin{array}{l}\text { Atrial fibrillation } \quad \ldots \\
\text { Atrial flutter } \\
\text { Supraventricular tachycardia } \\
\text { Ventricular tachycardia }\end{array}$ & $\begin{array}{ll}\ldots & \cdots \\
\cdots & \cdots \\
\cdots & \cdots\end{array}$ & & \\
\hline & & 56 & 40 \\
\hline
\end{tabular}

Most of the patients were taking digitalis and received the usual maintenance dose on the day of the procedure. None had shown evidence of digitalis intoxication at the time of countershock. No patient had received any other antiarrhythmic preparation before the countershock procedure. Only two patients, both cases of postmitral valvotomy, had been on anticoagulation therapy before the procedure. No premedication sedative was given. Most of the patients were outpatients. In those cases treated in the afternoon lunch was omitted. Otherwise there was no restriction of meals on the day of the countershock.

Diazepam was given very slowly intravenously in multiples of 5-mg doses to achieve transitory analgesia-amnesia necessary for the direct-current shock. In 31 cases the total dose ranged from 10 to $20 \mathrm{mg}$. In 20 cases 20 to $40 \mathrm{mg}$ was injected. Two patients required $70 \mathrm{mg}$ to induce sleepiness and amnesia. Quiet conversation was continued with the patient until he no longer responded. At this stage he was considered to be in an optimal state for shock. Except in two instances where the patient became transiently apnoeic there were no cases of adverse reaction at the time of intravenous administration of diazepam. Neither patient required assisted ventilation. It is possible that in these particular instances the diazepam had been injected too rapidly. The blood pressure was checked manually during the induction of sleep and again after the shock procedure. No significant change of blood pressure was noticed in any patient. After the onset of sleep countershock was delivered by means of shoulder-blade and anterior chest paddles. Energy applied was usually 100 joules (watt-seconds) initially, and if unsuccessful 200 and then 300 joules were used. All the patients were awake and responsive though drowsy immediately after the shock procedure. Cardioversion was successful in 40 out of 56 procedures. Most failures occurred in the cases of chronic rheumatic heart disease.
The drowsiness after diazepam seemed to last for about half an hour in most of our cases. Occasional patients remained somnolent for several hours. However, amnesia lasted several hours in one patient, a 40-year-old Irish priest who underwent cardioversion for atrial fibrillation persisting after mitral valvotomy. He had required $40 \mathrm{mg}$ of diazepam to induce anaesthesia. After a day admission he drove home some 100 miles $(160 \mathrm{~km}) . \mathrm{He}$ arrived safely but had no recollection of the journey.

\section{Discussion}

Intravenous diazepam is a valuable method of securing analgesiaamnesia for direct-current cardioversion. The avoidance of the frequent incidence of apnoea and premature ventricular contractions reported with the use of intravenous barbiturate anaesthesia (Muenster et al., 1967) is an advantage with the use of intravenous diazepam as the sole agent for analgesia-amnesia. Hendrix (1969) reported Cheyne-Stokes respiration in two elderly patients with chronic pulmonary disease. We did not encounter this complication. Because of the occasional case of apnoea, intravenous diazepam is best administered slowly, and facilities for assisted ventilation should be available in case of need. Winters et al. (1968) used oxygen for five minutes before and during induction of sleep in the cardioversion procedure to prevent risks of arterial hypoxaemia. From our experience, we believe that the risk of hypoxaemia is a theoretical one and that there is no need for oxygen with the diazepam method.

As in the practice of Muenster et al. (1967) our patients received digitalis, the usual maintenance dose on the day of the countershock. We do not feel that the wait involved in withholding digitalis for elective cardioversion is merited unless there has been evidence of digitalis toxicity. While many authors (Nutter and Massumi, 1965; Kahler et al., 1967; Muenster et al., 1967; Winters et al. 1968) administered quinidine before conversion, we did not do so because we wished to avoid quinidine toxicity, especially as its use in maintaining sinus rhythm is still controversial. Gunning et al. (1970) found that quinidine had no significant effect in the maintenance of sinus rhythm in a controlled long-term trial after cardioversion.

We have had no adverse experience from a general avoidance of anticoagulation. However, the $1 \%$ risk of systemic or pulmonary embolism following cardioversion of chronic atrial fibrillation, especially in rheumatic heart disease, is an avoidable complication with the use of previous anticoagulation (Lown, 1967).

Persisting amnesia as a complication of intravenous diazepam has often been reported (Thornton and Clarke, 1970). Dense amnesia generally lasts not more than 10 minutes, and it would be wise to have patients stay in hospital at least until their powers of memory return after treatment. The prolonged amnesia in one of our patients seems to have been an unusual reaction.

It is not the purpose of this paper to consider the long-term effect of electric shock therapy for cardiac arrhythmias. Even if sinus rhythm does not persist in the more chronic heart disorders, we regard as important the improvement in cardiac output by restoration of sinus rhythm in patients with atrial fibrillation and cardiac failure. We have described elsewhere (Somers et al., 1971) our experiences in the treatment of atrial arrhythmias in endomyocardial fibrosis. With the use of intravenous diazepam cardioversion can be readily mastered by the general physician at an outpatient service. In our practice one operator with an assistant controlling the cardioverter can manage the cardioversion with intravenous diazepam.

We are grateful to British Heart Foundation for the continuing support of our programme in cardiology and to Dr. John Garrod, of Roche Products Ltd., England, for generous supplies of diazepam (Valium). We thank Mr. John Milton and Mr. Herman Sebatta of the Cardiac Catheterization Laboratory. One of us (K.S.) was in receipt of support from the British Heart Council. 


\section{References}

Gunning, J. F., Kristinson, A., Miller, G., and Saunders, K. (1970). British Heart fournal, 32, 462 .

Hendrix, G. H. (1969). Southern Medical fournal, 62, 483.

Kahler, R. L., Burrow, G. N., and Feliq, P. (1967). Fournal of the American Medical Association, 200, 997.

Kernohan, R. J. (1966). Lancet, 1, 718.

Kernohan, R. J. (1966). Lancet, 1, 718. of a Symposium, Royal Society of Medicine, p. 82 . Bristol, Wright.

Lebowitz, W. B. (1969). Connecticut Medicine, 33, 173

Lown, B. (1967). British Heart fournal, 29, 469.

Lown, B., Amarsingham, R., and Neuman, J. (1962). Fournal of the American Medical Association, 182, 548.
Muenster, J. J., Rosenberg, M. S., Carleton, R. A., and Graettinger, J. S. (1967). Fournal of the American Medical Association, 199, 758.

Nutter, D. O., and Massumi, R. A. (1965). New England Fournal of Medicine, 650, 273.

Somers, K., Gunstone, R. F., Patel, Ashvin K., and D'Arbela, P. G. (1971). In preparation

Thornton, J. A., and Clarke, P. F. R. (1970). British Medical fournal, 2, 732. Turkel, R. A., and Lemmert, W. A. (1969). Southern Medical fournal, 62, 61. Winters, W. L., McDonough, M. T., Hafer, J., and Dietz, R. (1968). Fournal of the American Medical Association, 204. 926 .

Woodbridge, J. H. (1969). Fournal of the Mississippi State Medical Association, 10,542 .

\title{
Baclofen in the Treatment of Spasticity*
}

\author{
P. HUDGSON, D. WEIGHTMAN
}

British Medical fournal, 1971, 4, 15-17

\section{Summary}

Baclofen $\dagger$ (Lioresal), a derivative of gamma-aminobutyric acid, was introduced in 1966 as a possible treatment for spasticity due to corticospinal tract lesions. Preliminary studies suggested that it may be more effective than other spasmolytic agents currently available, and a double-blind controlled trial in a group of 23 patients against placebo has shown it to be significantly more effective.

\section{Introduction}

The treatment of spasticity due to spinal cord and other neurological lesions has long been unsatisfactory. Intrathecal injections of phenol (Nathan, 1959) may produce significant improvement in some patients for several months, though the risks of increasing weakness in the lower limbs and interfering with bladder function are obvious disadvantages. Various problems attend the drug treatment of spasticity, many of the agents introduced being quite ineffective when given by mouth. Chlordiazepoxide and diazepam are probably the most helpful preparations in common use, but both are likely to make patients unacceptably drowsy when effectively reducing spasticity. These drugs probably exert their effect by acting on spinal interneurones (Cook and Nathan, 1967) but their tranquillizing effects suggest that modification of supraspinal influences may also be involved.

The basis for a more rational approach to the problem has been provided by recent studies of spinal cord pharmacology (Lancet, 1970). Attention has been focused on gamma-aminobutyric acid, which depresses all types of spinal neurones (Curtis and Watkins, 1965) and inhibits monosynaptic and multisynaptic reflex activity in the experimental animal. A preliminary report by Birkmayer, Danielczynk, and Weiler (1967) suggested that the gamma-aminobutyric acid derivative

* An abbreviated version of this paper was read at an International Symposium on Current Aspects of Muscle Spasticity, Vienna, April 1971.

Proposed approved name.

Royal Victoria Infirmary, Newcastle upon Tyne NE1 4LP P. HUDGSON, M.R.C.P., M.R.A.C.P., Physician in Neurology

University of Newcastle upon Tyne, Newcastle upon Tyne D. WEIGHTMAN, Assistant in Medical Statistics beta-(4-chlorophenyl)-gamma-aminobutyric acid, baclofen (Lioresal), was useful in the control of spasticity, particularly in spinal cord lesions. This was supported by the studies of Pedersen, Arlien-Søborg, Grynderup, and Henriksen (1970) and of Jones, Burke, Marosszeky, and Gillies (1970), the latter a placebo-controlled trial in six patients.

\section{Preliminary Study}

Six patients with severe spasticity in their lower limbs due to spinal cord disease (five with multiple sclerosis and one with severe residual spastic paraparesis after surgical removal of a dorsal neurofibroma) were admitted to this study. In each case baclofen was administered in a single intravenous injection of $25 \mathrm{mg}$ and orally in doses of $10 \mathrm{mg}$ thrice daily for 10 days. An attempt was made to monitor the effects of the intravenous injection by needle electromyography, but interpretation of the data so obtained was virtually impossible because of interference due to flexor spasms induced in the muscles sampled. However, a trend in favour of the drug was thought to be present and there was certainly an appreciable improvement in spasticity on clinical examination in each patient (Barwick and Hudgson, 1967). This was also the subjective impression of all the patients, though one (a middle-aged woman with neurofibromatosis) was unable to tolerate the oral preparation for more than two days because of nausea and vomiting (she had previously reported nausea and vertigo during the intravenous injection). Another patient had three major epileptic seizures and developed a confusional state when she was on the oral preparation. However, the situation was complicated in her case by the fact that she had moderately severe cerebral demyelination with dementia as well as spinal cord disease in addition to a fever due to urinary tract infection.

\section{Double-blind Trial}

The formal double-blind cross-over trial of baclofen was begun in mid-1968 and at the time of closing the trial 23 patients had completed it. To standardize the conditions of the trial as much as possible it was decided to limit entry to patients with lower limb spasticity due to spinal cord disease. Of the 23 patients 18 were suffering from multiple sclerosis and were in remission, but with severe residual neurological deficits; two had myelopathies associated with cervical spondylosis; one had motor neurone disease with unusually severe spasticity in his lower limbs; one was a case of familial spastic paraplegia; and one woman had a slowly progressive spastic paraparesis of uncertain nature, possibly "spinal" multiple sclerosis. Their 